\title{
Performance Evaluation and Economic Analysis of a Domestic Solar Cooker
}

\author{
Augustine U. Iwuoha, Briggs M. Ogunedo \\ Department of Mechanical Engineering, Imo State University, Owerri, Nigeria \\ Email: briggsogunedo@gmail.com
}

How to cite this paper: Iwuoha, A.U. and Ogunedo, B.M. (2021) Performance Evaluation and Economic Analysis of a Domestic Solar Cooker. Open Access Library Journal, 8: e7263.

https://doi.org/10.4236/oalib.1107263

Received: February 24, 2021

Accepted: March 27, 2021

Published: March 30, 2021

Copyright $\odot 2021$ by author(s) and Open Access Library Inc.

This work is licensed under the Creative Commons Attribution International License (CC BY 4.0).

http://creativecommons.org/licenses/by/4.0/

(c) (i) Open Access

\begin{abstract}
The thermal performance of a Domestic Solar Cooker (DSC) was evaluated in this study in accordance with the Society of Agricultural Engineers Standard (ASAE S58, 2003). The DSC is a parabolic solar cooker type with a focal point of $1 \mathrm{~m}$, diameter of $2.14 \mathrm{~m}$, absorber surface area of $0.07 \mathrm{~m}^{2}$, concentrator surface area of $3.84 \mathrm{~m}^{2}$, and concentration ratio of 54 which uses a glass mirror as its reflector. Results of the study show that stagnation temperature of $320^{\circ} \mathrm{C}$ was attained at a heating rate of $5.4^{\circ} \mathrm{C} / \mathrm{min}$. The first and second figures of merit values were $0.623 \mathrm{~m}^{2} \mathrm{~K} / \mathrm{W}$ and $0.464 \mathrm{~m}^{2} \mathrm{~K} / \mathrm{W}$ respectively, indicating that the DSC absorbs $31.82 \mathrm{~J}$ of radiated heat energy from the DSC in 1 second while the heat load ( $4 \mathrm{~kg}$ of water) absorbs $0.0512 \mathrm{~J}$ of the radiated heat for every degree rise in the pot temperature in a second. The cooking power of the DSC is $618.5 \mathrm{~W}$, and the thermal efficiency is $48.67 \%$. The solar insolation during the test is $453.81 \mathrm{~W} / \mathrm{m}^{2}$. This value is observed to be lower than what was obtained from similar solar cookers in published data implying that the DSC will perform better under higher solar insolation values. The cost of producing the DSC is N 12,920.00 (US\$ 34) and with a payback time of 153 days, comparatively the DSC is judged to be viable economically.
\end{abstract}

\section{Subject Areas \\ Chemical Engineering \& Technology}

\section{Keywords}

Solar, Cooker, Exergy, Evaluation, Economic, Analysis

\section{Introduction}

Cooking is an important aspect in human life, because the energy needed to carry out human activities is gotten from the food we eat. The main energy 
sources for cooking include: electricity, fossil fuel derivatives (Liquefied Petroleum Gas, kerosene), biomass (fuel wood, charcoal, animal dung, poultry droppings). These conventional sources have advantages of quick heating, availability, cost-friendliness, et cetera. However, demerits abound; for instance, the huge energy consumption of electric stove outweighs its advantage of quick heating. Also, the hazards associated with the use of Liquefied Petroleum Gas (LPG) make it dreadful to some persons, while the use of firewood and charcoal is the major contributor to deforestation and global warming. In the rural areas of $\mathrm{Ni}$ geria, biomass is the main energy source for cooking. This demand for biomass has led to increase in the rate of desert encroachment in the northern region as at least 3500 hectares of its arable land are lost annually to the desert [1]. The southern region of Nigeria is not left out of this negative effect as it has recorded an increase in the rate of gully erosion due to deforestation, which is an anthropogenic cause of gully erosion in this region [2]. An alternative to the use of fuel wood in the rural areas of Nigeria will be the use of solar cookers. Iwuoha and Ogunedo [3] opine that solar cooking is one of the simplest, safest, clean, environmentally friendly, and most convenient ways to cook without consuming conventional fuels or heating up the kitchen.

The technology employed in the design of solar cookers can be classified into 2 main groups based on the mode of operation: Concentrating type of solar cookers and Non-Concentrating type of solar cookers. Concentrating solar cookers operate by concentrating reflected rays of the sun on the absorber plate while the non-concentrating solar cookers heat up food substances by using greenhouse effect. Figure 1 gives an illustration of the classification of solar cookers.

Solar oven cookers are also called solar box cookers. It is mainly a rectangular or square box with a transparent glass cover to trap sunlight into it, thereby utilizing the principle of greenhouse effect to cook. An insulator is introduced between the outer and inner walls of the oven in order to reduce heat losses from the bottom and sides of the cooker. The drawback of this type of cooker is the challenge of tracking the sun by changing the inclination of the mirror every 20 30 minutes [4].

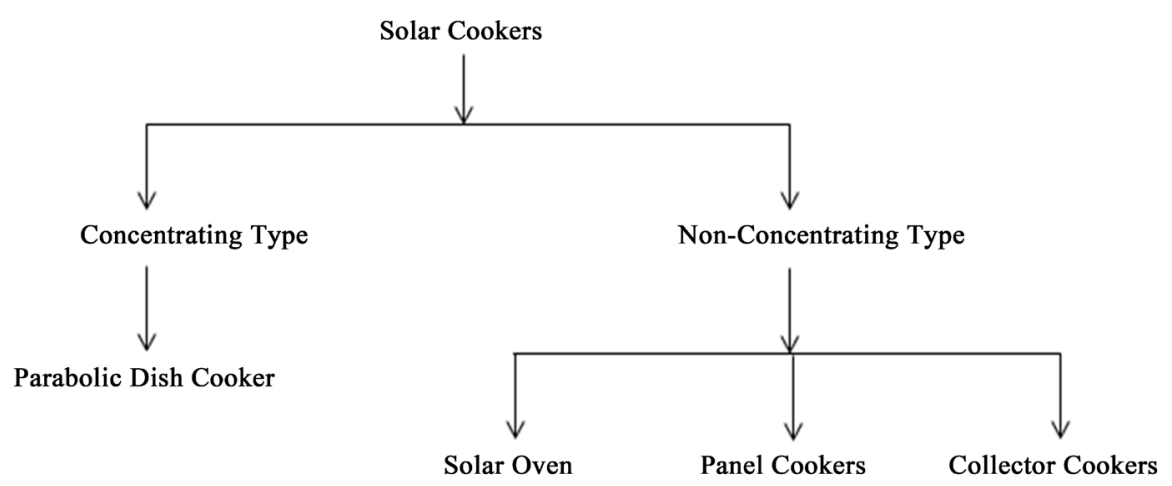

Figure 1. Classification of solar cookers. 
The panel cookers are similar to the solar oven in design and principle of operation. However, it differs in the sense that it incorporates large reflective panels which focus sun rays on the cooking box glass cover, thereby increasing the temperature in the solar box more than what would be attained in the solar oven type. Studies [5] [6] [7] have shown that the efficiency of panel cooker can be enhanced using dual reflective panels. In a later study, Farooqui [8] showed that with an aspect ratio and optimized tilt angles of $2.66,45^{\circ}$ and $98^{\circ}$ respectively, the cooker can operate for at least 6 hours a day without requiring solar tracking. Farooqui [9] also proposed another means of tracking system for solar cookers by using a gravity based tracking mechanism that drives a timing belt mounted on circular wooden disc. Result of the study shows that the system can help steady cooking for up to 6 hours per day before manual tracking is required.

The collector cooker is made up of three main parts viz: a flat plate solar collector, heating medium, and cooking pot. The flat plate solar collector is a very large heat absorbing plate, usually a large sheet of copper or aluminium chemically etched/painted black in order to effectively absorb the solar radiation for maximum efficiency. The heating medium is oil which runs in aluminium/copper pipes underneath the flat plate solar collector within an insulated enclosure. The absorbed solar radiations heat up the oil which then transfers the heat to the cooking pot through insulated aluminium copper pipe extended from the insulated enclosure to the cooking pot base where the absorber plate (cooking pot) is placed for food to be cooked. Farooqui [10] designed and constructed a vacuum collector cooker which utilized a one dimensional solar tracker to track the sun and has a thermal power transfer efficiency between $20 \%$ and $30 \%$, while temperatures of up to $250^{\circ} \mathrm{C}$ was achieved.

The parabolic dish cooker operates by concentrating solar radiations (through the aid of a parabolically shaped reflective surface) to the bottom of the absorber plate, causing heating of the pot to be achieved. The reflective surface could be made of Mylar sheet, polished Aluminium, glass mirror, et cetera. Parabolic cookers have been found to have an advantage of developing high temperatures for cooking. Ashok [11] noted that these cookers acquire concentration ratios of up to 50 and temperatures of up to $300^{\circ} \mathrm{C}$. Dasin [12] noted that concentrating cookers are the only class of solar cookers that are truly suitable for frying, as the temperatures at the focus can rival that of conventional electric gas or wood fired stoves. However, the low thermal efficiency of existing parabolic dish cookers within the rural areas of the country has become an impediment to the wide spread commercial use of the DSC. In view of the advantages DSCs offer, Iwuoha and Ogunedo [3] in their work opine that a domesticated application of solar cooking will help alleviate the demerits of fuel wood cooking. Therefore, in this study an evaluation of the thermal effectiveness of an existing domestic solar cooker and the comparative cost benefits thereof was carried out, establishing that at a thermal efficiency of $48.67 \%$ the study improved on previous work done by Dasin [12] in this area. 


\section{Materials and Method}

The Domestic Solar Cooker (DSC) under investigation is designed using the technology of Concentrated Solar Panels (CSPs). Here, the sun rays are made to converge at a focal point through the aid of a reflective surface parabolic dish and the cooking pot (absorber plate) is usually positioned or located at this point. The component parts of the DSC are as follows: the parabolic dish (reflective surface), bracket (aids in manual tracking of the sun), dish stand, dish base, reflector material, cooking pot (absorber plate). The absorber plate is made up of Aluminum; the reflective material used is glass mirror, while other components are made of low carbon steel. Table 1 and Table 2 give information on the material selection and design specification of the DSC under investigation.

\subsection{Evaluation Protocol}

In carrying out the evaluation of the DSC, the method stipulated by Society of Agricultural Engineers Standard (ASAE S58, 2003) as presented by Funk [13] was adopted. Variables that affect the outcome of the test were classified into uncontrollable and controllable variables. Uncontrollable variables are those variables that cannot be manipulated by the operator because they are weather dependent. These include factors such as wind, ambient temperature, insolation, and solar altitude. Controllable variables refer to all variables that could be manipulated directly by the test operator during the test period. These include load

Table 1. Material selection.

\begin{tabular}{cccc}
\hline S/n & Component Parts & Material Used & Reasons \\
\hline 1 & $\begin{array}{c}\text { Parabolic dish, Bracket, } \\
\text { Dish stand, and Base. }\end{array}$ & Low carbon steel & $\begin{array}{c}\text { Ductile and malleable. } \\
\text { High tensile strength. } \\
\text { Weld ability is high }\end{array}$ \\
2 & Reflector & Glass mirror & $\begin{array}{c}\text { High optical reflectance/heat transmittance. } \\
\text { Ductile and malleable. High resistance to } \\
\text { corrosion. High thermal conductivity and } \\
\text { food hygiene friendly. }\end{array}$ \\
\hline
\end{tabular}

Table 2. DSC design specifications.

\begin{tabular}{cc}
\hline Parameter & Value \\
\hline Dish diameter & $2.14 \mathrm{~m}$ \\
Dish depth & $0.28 \mathrm{~m}$ \\
Dish stand & $0.625 \mathrm{~m}$ \\
Concentrator total surface area $\left(A_{T}\right)$ & $3.84 \mathrm{~m}^{2}$ \\
Absorber surface area $\left(A_{s}\right)$ & $0.07 \mathrm{~m}^{2}$ \\
Reflectivity of reflector material & $99 \%$ \\
Focal point & $1 \mathrm{~m}$ \\
Concentration ratio $\left(A_{T} / A_{s}\right)$ & 54 \\
\hline
\end{tabular}


value, solar tracking, and temperature measurement.

\subsubsection{Uncontrollable Variables}

The test was conducted between 10:00 and 14:30 hours (Nigerian Time) under clear sky condition because during this period, the solar zenith angle was moderately constant at the test location. The solar insolation values for the period of the test ranged from $452 \mathrm{~W} / \mathrm{m}^{2}$ to $463 \mathrm{~W} / \mathrm{m}^{2}$ with ambient temperature ranging from $33^{\circ} \mathrm{C}$ to $36^{\circ} \mathrm{C}$. The temperature range was chosen because it allows for stability and repeatability of test results in any part of the country as most regions of the country experience the same temperature ranges. In order to ensure that the heat loss due to free air convection is kept at a minimum, and for achieving consistency in results, the tests were performed within the wind speed of $1.0 \mathrm{~m} / \mathrm{s}$ to $1.39 \mathrm{~m} / \mathrm{s}$. Table 3 gives a summary of the test conditions for uncontrolled variables.

\subsubsection{Controllable Variables}

The load value refers to the mass of food product used during the test. $4 \mathrm{~kg}$ of water was used to test for the figures of merit, energy efficiency, cooking power and quality of the cooker. Manual tracking was employed during the test to track the movement of the sun. This is to ensure that the reflected rays are constantly focused on the absorber plate bottom (pot). Temperature readings for both sensible heating and stagnation tests were taken from the pot by making sure the probe of the digital thermometer is secured $10 \mathrm{~mm}$ above the pot bottom.

\subsection{Performance Evaluation Procedure}

The test location is Owerri with latitude of $5.4891^{\circ} \mathrm{N}$ and longitude of $7.0176^{\circ} \mathrm{E}$. The test was conducted between 04/03/2018 and 24/03/2018 during clear sky days. The pot average temperature $\left(T_{p}\right)$ during the determination of the first figure of merit and the average water temperature $\left(T_{w}\right)$ during the determination of the second figure of merit were recorded every 10 minutes from $40^{\circ} \mathrm{C}$ because within 10 minutes, it is assumed that the minor fluctuations in heat loss due to ambient temperatures and wind speed variability will be negligible, while the

Table 3. Test condition of uncontrolled variables.

\begin{tabular}{|c|c|c|c|}
\hline Variable & Value & Reason & $\begin{array}{l}\text { Measurement } \\
\text { Instrument/Method used }\end{array}$ \\
\hline Wind & $1.0 \mathrm{~m} / \mathrm{s}-1.39 \mathrm{~m} / \mathrm{s}$ & $\begin{array}{l}\text { For minimum heat loss due to } \\
\text { free air convection and } \\
\text { consistency in test result. }\end{array}$ & MT130 cup anemometer \\
\hline Solar Insolation & $\begin{array}{c}452 \mathrm{~W} / \mathrm{m}^{2}-457 \\
\mathrm{~W} / \mathrm{m}^{2}\end{array}$ & $\begin{array}{l}\text { Minimize variability of results } \\
\text { due to thermal inertia. }\end{array}$ & $\begin{array}{l}\text { Mac Solar digital } \\
\text { pyranometer }\end{array}$ \\
\hline $\begin{array}{l}\text { Ambient } \\
\text { Temperature }\end{array}$ & $33^{\circ} \mathrm{C}-36^{\circ} \mathrm{C}$ & $\begin{array}{l}\text { For stability and repeatability of } \\
\text { results in other regions of the } \\
\text { country. }\end{array}$ & $\begin{array}{l}\text { TL8009 mini digital } \\
\text { thermometer. }\end{array}$ \\
\hline Test time & $\begin{array}{l}\text { 10:00-14:30 hours } \\
\text { (Nigerian Time) }\end{array}$ & $\begin{array}{c}\text { Moderately constant Solar } \\
\text { Azimuth angle }\end{array}$ & $\begin{array}{l}\text { Zenith Angle } \\
=\text { Latitude - declination }\end{array}$ \\
\hline
\end{tabular}


heat gain variability due to gradual sun angle changes will be constant [13]. Also, at $40^{\circ} \mathrm{C}$, the water temperature is higher than the ambient air temperature, thereby creating condition for heat losses. The solar insolation $\left(I_{s}\right)$ and ambient temperature $\left(T_{a}\right)$ were recorded for corresponding temperature intervals.

\section{Performance Indicators}

\section{First figure of merit $\left(F_{1}\right)$}

This is also called stagnation temperature test. It gives information on the amount of the maximum temperature the pot can attain at a particular level of solar insolation. Mathematically, it is expressed as:

$$
F_{1}=\frac{T_{p}-T_{a}}{I_{s}}
$$

where

$T_{p}=$ Pot stagnation temperature,

$T_{a}=$ Ambient air temperature,

$I_{s}=$ Solar insolation on the horizontal surface.

The slope of the curve for $F_{1}$ against temperature difference gives information on the minimum area of the pot bottom needed to absorb 1 Joule of heat energy radiated to the pot from the solar cooker per second due to the temperature difference. This first figure of merit test was performed under a no load condition, i.e. the empty pot was placed on the pot stand while the sun rays were focused at the pot bottom.

\section{Second figure of merit $\left(F_{2}\right)$}

It quantifies the amount of heat that can be transferred from the pot to the load it contains. It could be called a sensible heating because during this test, heat is transferred from the pot to the water (load) without changes in the macroscopic variables of the pot. Mathematically, it is expressed using Equation (2).

$$
F_{2}=\frac{F_{1}\left(M_{w} C_{w}\right)}{A \cdot \tau} \ln \left[\frac{\left(1-\left(T_{w i}-T_{a v}\right) /\left(F_{1} \cdot I_{s}\right)\right)}{\left(1-\left(T_{w f}-T_{a v}\right) /\left(F_{1} \cdot I_{s}\right)\right)}\right]
$$

where $M_{w}$ and $C_{w}=$ mass of the water in the pot and heat capacity of water respectively,

$A=$ aperture area of the cooker,

$\tau=$ time difference during which water was heated from an initial temperature $T_{w i}$ to the final temperature $T_{w f}$

$I_{s}=$ average solar radiation on a horizontal surface, and

$T_{a v}=$ average ambient temperature during the experiment.

The second figure of merit was performed under a full load condition.

Cooking power $(P)$

This parameter indicates the sensible heat gain of the cooker, and it is the best indicator or measure of the cooker's ability to effectively heat food. This parameter is of great importance to the end users of the product. It is expressed mathematically as: 


$$
P=\frac{\text { Heat gained by load }}{\text { Heating time }}=\frac{M_{w} C_{w} \Delta T}{\tau}=\frac{M_{w} C_{w}\left(T_{w f}-T_{w i}\right)}{\tau}
$$

Due to the climatic condition of the test location, the test was carried out with $I_{s}$ below $700 \mathrm{~W} / \mathrm{m}^{2}$ therefore, in order to enable comparison of results from different locations and dates, Equation (3) was standardized by correcting it to a standard insolation of $700 \mathrm{~W} / \mathrm{m}^{2}$ as shown in Equation (4).

$$
P_{\text {std }}=\frac{P \times 700}{I_{s}}
$$

where $P_{s t d}=$ Standard Cooking Power.

Equation (4) also known as standardized cooking power and is a suitable tool for comparative analysis between concentrated solar cookers.

Thermal energy efficiency $(\eta)$

The thermal energy efficiency indicates how the cooker utilizes the thermal energy in the reflected solar rays for heating. It is expressed as:

$$
\eta=\frac{\text { Output }}{\text { Input }}=\frac{M_{w} C_{w}\left(T_{w f}-T_{w i}\right)}{I_{s} A \tau}
$$

\subsection{Exergy Analysis}

According to Ogunedo and Okoro [15], exergy could be conceptualized to mean the maximum amount of energy available/maximum work that can be done by a system existing at a given state. It helps quantify losses in a system and identify locations where these losses occur. The indicators used for the analysis are explained below.

\section{Exergy input $\left(\varphi_{i}\right)$}

This is the maximum available energy from solar radiation to the solar cooker. It is expressed using Equation (6).

$$
\varphi_{i}=I_{s} A \tau\left[1+\left(\frac{T_{a}}{T_{s}}\right)^{4}\left(\frac{1}{3}\right)-\left(\frac{4}{3}\right)\left(\frac{T_{a}}{T_{S}}\right)\right]
$$

where $T_{a}$ and $T_{s}$, respectively, indicate the ambient air temperature during the experiment and the surface temperature of the sun

Exergy output $\left(\varphi_{o}\right)$

This is the amount of energy made available by the solar cooker for the purpose of heating. It was evaluated using Equation (7).

$$
\varphi_{o}=M_{w} C_{w}\left(T_{w f}-T_{w i}\right)-M_{w} C_{w} T_{a} \ln \left[\frac{T_{w f}}{T_{w i}}\right]
$$

\section{Exergy efficiency $(\psi)$}

This gives an indication as to how the cooker can effectively utilize the available solar energy in heating food substances. It is expressed in Equation (8) as: 


$$
\psi=\frac{\text { Exergy output }}{\text { Exergy input }}=\frac{M_{w} C_{w}\left(T_{w f}-T_{w i}\right)-M_{w} C_{w} T_{a} \ln \left[\frac{T_{w f}}{T_{w i}}\right]}{I_{s} A \tau\left[1+\left(\frac{T_{a}}{T_{s}}\right)^{4}\left(\frac{1}{3}\right)-\left(\frac{4}{3}\right)\left(\frac{T_{a}}{T_{S}}\right)\right]}
$$

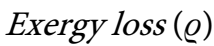

This is the amount of destroyed energy in the cooking device within the time under investigation. Equation (9) was used to determine this parameter.

$$
\varrho=\varphi_{i}-\varphi_{o}
$$

\section{Exergy loss coefficient $(\xi)$}

This is the amount of available energy destroyed per second due to systems irreversibility for every degree change in temperature between the heating load and ambient air over a square meter area of the dish. It is expressed using Equation (10).

$$
\xi=\frac{\varrho}{A \tau\left(T_{w f}-T_{a}\right)}
$$

The irreversibility of the system in this context means the heat loss due to rays not properly focused at the base of the absorber. This could be due to the nature of the reflective material used and the perfectness of the parabolic dish shape. The larger the temperature differences between the heating load and the ambient air, the lower the loss.

\section{Result and Discussion}

Table 4 gives the result of stagnation test carried out on the DSC. Results obtained from carrying out a 4 hours stagnation test on the DSC reveal that the maximum temperature attained by the pot is $320^{\circ} \mathrm{C}$ and this occurred between 13:50 to 14:00 hours. From Figure 2, as the pot temperature $\left(T_{p}\right)$ varies with time, heating to a stable temperature range of $300^{\circ} \mathrm{C}$ to $320^{\circ} \mathrm{C}$ by the DSC is done at an average rate of $5.4^{\circ} \mathrm{C} / \mathrm{min}$. This means that the pot temperature increases by an average of $5.4^{\circ} \mathrm{C}$ every minute until it attained $300^{\circ} \mathrm{C}$. The sun was manually tracked four times during the test, causing the DSC to have moved $60^{\circ}$ away from its initial position (IP) at the start of the test.

A similar trend was observed for $F_{1}$ as shown in Figure 3. This is mainly due to the fact that $F_{1}$ is temperature dependent. The maximum and minimum values of $F_{1}$ are $-0.002 \mathrm{~m}^{2} \mathrm{~K} / \mathrm{W}$ and $0.623 \mathrm{~m}^{2} \mathrm{~K} / \mathrm{W}$ occurring at $32^{\circ} \mathrm{C}$ and $320^{\circ} \mathrm{C}$ respectively. The negative value obtained as the minimum $F_{1}$ was because during the first 10 minutes of the experiment, the temperature of the pot was observed to be a degree lower than the ambient temperature.

Result of the relationship between $F_{1}$ and temperature difference between the pot temperature and ambient temperature as shown in Figure 4 reveal that $0.0022 \mathrm{~m}^{2}$ area of the pot bottom absorbs 1 Joule of heat energy in 1 second. Hence, since the pot has an area of $0.07 \mathrm{~m}^{2}$, it absorbs 31.82 Joules of radiated 
Table 4. Stagnation test result.

\begin{tabular}{|c|c|c|c|c|c|}
\hline Time & $I_{s}\left(\mathrm{~W} / \mathrm{m}^{2}\right)$ & Velocity $(\mathrm{m} / \mathrm{s})$ & $T_{p}\left({ }^{\circ} \mathrm{C}\right)$ & $T_{a}\left({ }^{\circ} \mathrm{C}\right)$ & Tracking angle \\
\hline 10:00-10:10 & 452 & 1 & 32 & 33 & \\
\hline $10: 10-10: 20$ & 452 & 1 & 98 & 33 & \\
\hline $10: 20-10: 30$ & 452 & 1 & 121 & 33 & \\
\hline 10:30-10:40 & 452 & 1.1 & 201 & 33 & $\mathrm{~S} 15^{\circ} \mathrm{W}$ (IP) \\
\hline 10:40-10:50 & 453 & 1 & 298 & 33 & \\
\hline 10:50-11:00 & 452 & 1.3 & 302 & 33 & \\
\hline 11:00-11:10 & 452 & 1 & 302 & 33 & \\
\hline 11:10-11:20 & 452 & 1 & 302 & 33 & \\
\hline 11:20-11:30 & 452 & 1 & 300 & 33 & \\
\hline 11:30-11:40 & 452 & 1 & 300 & 33 & $\mathrm{~S} 30^{\circ} \mathrm{W}$ from IP \\
\hline 11:40-11:50 & 452 & 1 & 300 & 33 & \\
\hline 11:50-12:00 & 452 & 1 & 300 & 33 & \\
\hline 12:00-12:10 & 452 & 1 & 300 & 33 & \\
\hline $12: 10-12: 20$ & 455 & 1 & 317 & 34 & \\
\hline $12: 20-12: 30$ & 455 & 1.3 & 311 & 34 & \\
\hline $12: 30-12: 40$ & 455 & 1.1 & 315 & 34 & \\
\hline $12: 40-12: 50$ & 455 & 1.3 & 301 & 34 & $\mathrm{~S} 45^{\circ} \mathrm{W}$ from IP \\
\hline 12:50-13:00 & 455 & 1.1 & 307 & 34 & \\
\hline 13:00-13:10 & 455 & 1.2 & 307 & 34 & \\
\hline $13: 10-13: 20$ & 455 & 1.3 & 301 & 34 & \\
\hline 13:20-13:30 & 455 & 1.3 & 300 & 34 & \\
\hline $13: 30-13: 40$ & 457 & 1 & 312 & 34 & \\
\hline 13:40-13:50 & 457 & 1 & 316 & 35 & \\
\hline 13:50-14:00 & 457 & 1 & 320 & 35 & $\mathrm{~S} 60^{\circ} \mathrm{W}$ from IP \\
\hline 14:00-14:10 & 457 & 1 & 318 & 35 & \\
\hline $14: 10-14: 20$ & 455 & 1 & 316 & 35 & \\
\hline 14:20-14:30 & 453 & 1 & 307 & 35 & \\
\hline
\end{tabular}

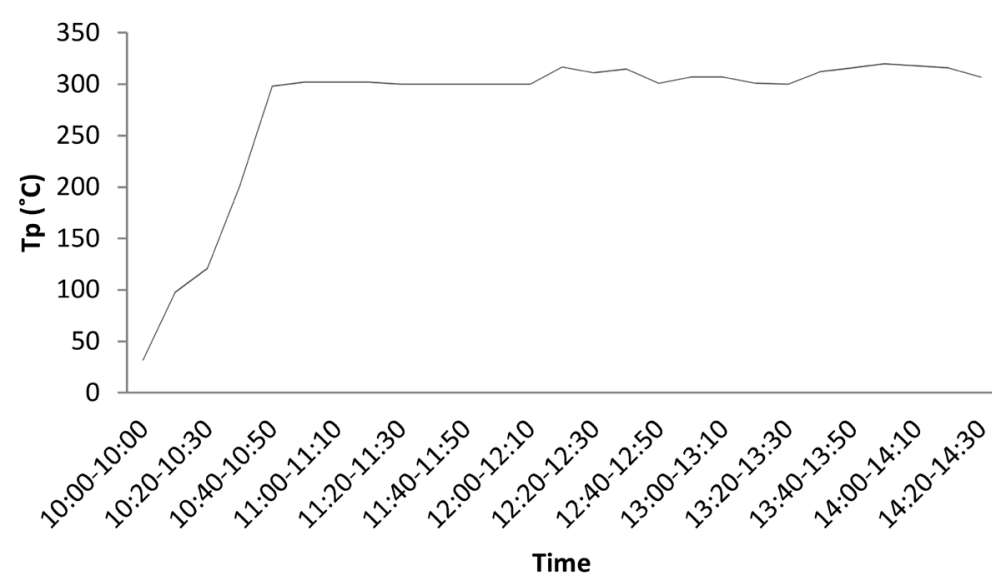

Figure 2. Variation of pot temperature with time. 


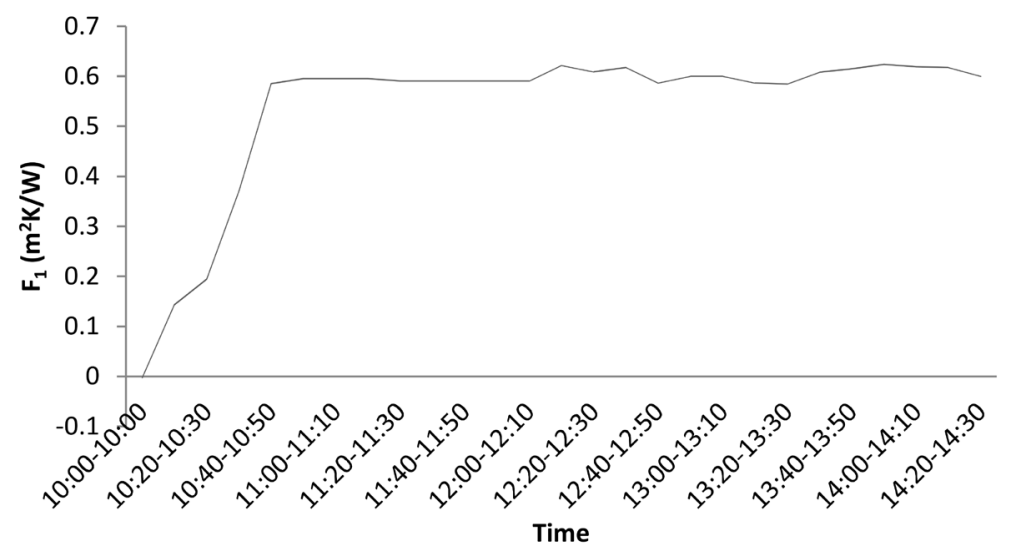

Figure 3. Variation of $F_{1}$ with time.

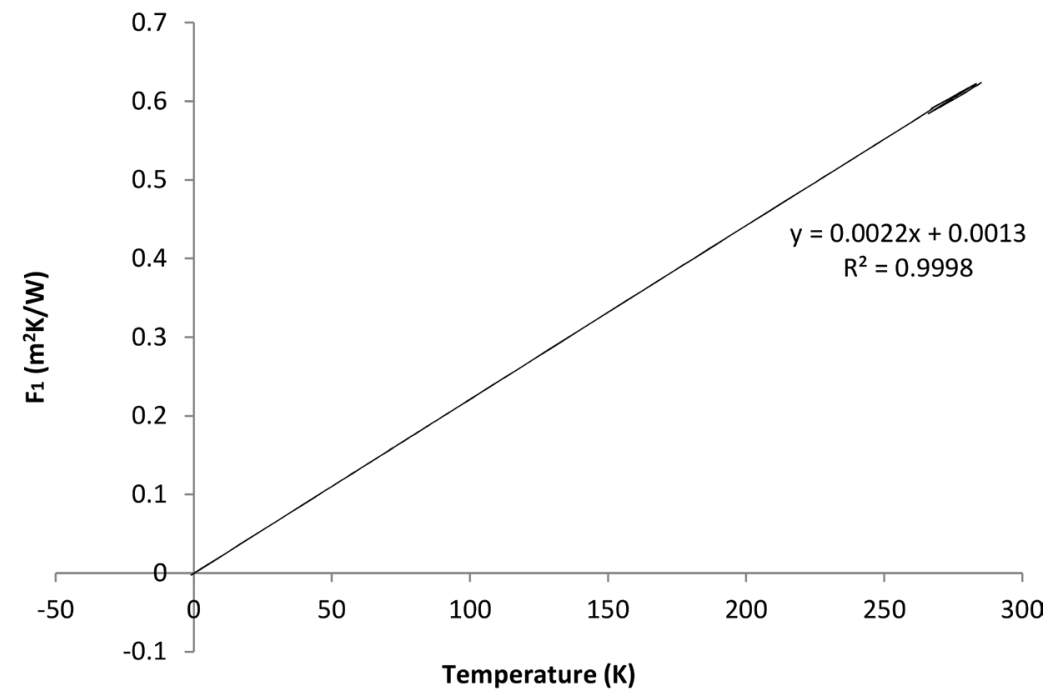

Figure 4. Variation of $F_{1}$ with temperature.

heat energy from the DSC in 1 second. These values obtained from $F_{1}$ show that at higher values of solar insolation, the DSC would perform brilliantly.

Equation (2) was used to determine the $F_{2}$ value of the DSC. The essence is to quantify the amount of heat absorbed by the load during the sensible test. Figure 5 shows that $0.7316 \mathrm{~W}$ of heat is absorbed from the pot per $\mathrm{m}^{2}$ for every degree rise in the pot temperature. hence, considering the area of $0.07 \mathrm{~m}^{2}$ of the aperture where the pot is been positioned, it means that $0.0512 \mathrm{~J}$ of heat is absorbed by the heat load ( $4 \mathrm{~kg}$ of water) for every degree rise in the pot temperature in a second.

The standardized cooking power was determined using Equation (4). Then, a single measure of performance was generated by plotting a graph of the standardized cooking power against temperature difference between the heat load and ambient air. A standardized cooking power at a temperature difference of $50^{\circ} \mathrm{C}$ is chosen as the cooking power of the DSC. A temperature difference of $50^{\circ} \mathrm{C}$ was chosen because according to the results obtained in the work of Funk [13], it strikes a balance between overemphasis on the start-up cooking power and 
stagnation temperature, and is just below the critical temperature where cooking begins to occur. This is also the temperature where the solar cooker succeeds or fails. A regression model was fit for the determination of the standardized cooking power after collecting data from 22 tests. The model as shown in Figure 6 and it reveals that the startup cooking power of the DSC is $1127.43 \mathrm{~W}$, occurring at a temperature difference of $35^{\circ} \mathrm{C}$. From this point, the cooking power is projected to reduce by $31 \mathrm{~W}$, with every $1^{\circ} \mathrm{C}$ difference in temperature. Using the regression model fit for the data, the standardized cooking power of the DSC is $618.5 \mathrm{~W}$.

The efficiency of the DSC was determined using equation 5. Average values of data obtained from 22 tests as shown in Table 5 were used.

From the data obtained, the overall thermal efficiency of the DSC is $48.67 \%$. This result is seen to be an improvement on an earlier work done in this area in Nigeria by Dasin [12] which had an efficiency of $17.5 \%$. Figure 7 shows a picture of the DSC in operation.

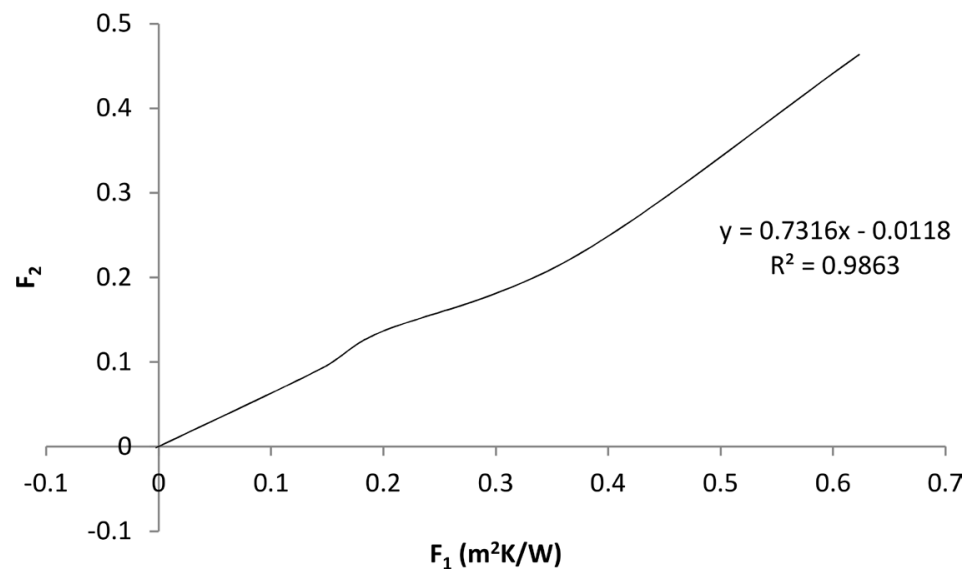

Figure 5. Variation of $F_{2}$ with $F_{1}$.

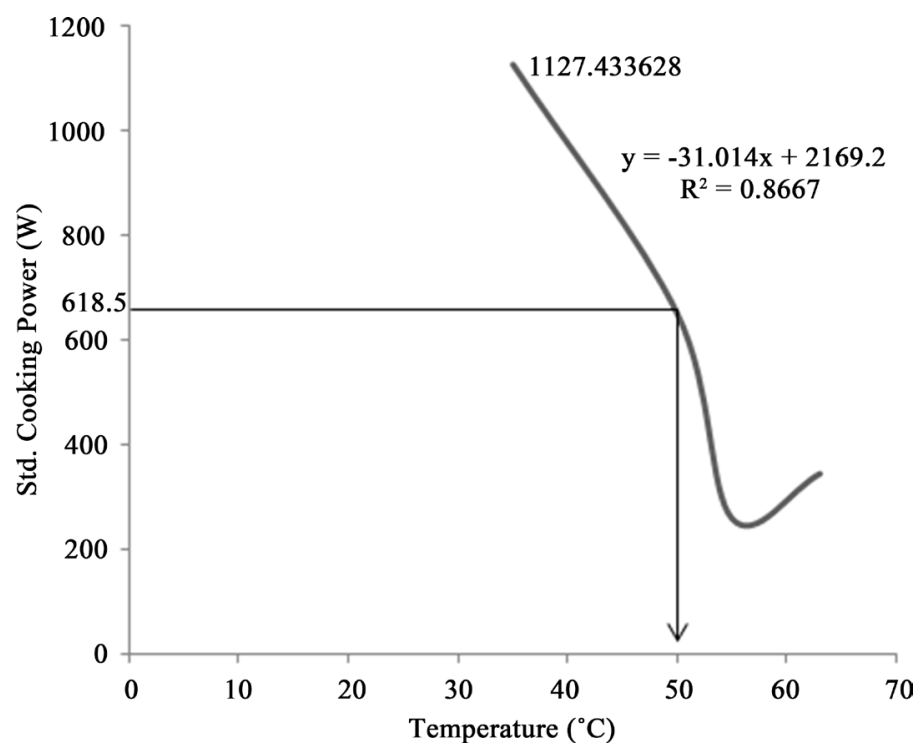

Figure 6. Variation of Std. Cooking power with temperature difference. 
Table 5. Data obtained for computing thermal efficiency.

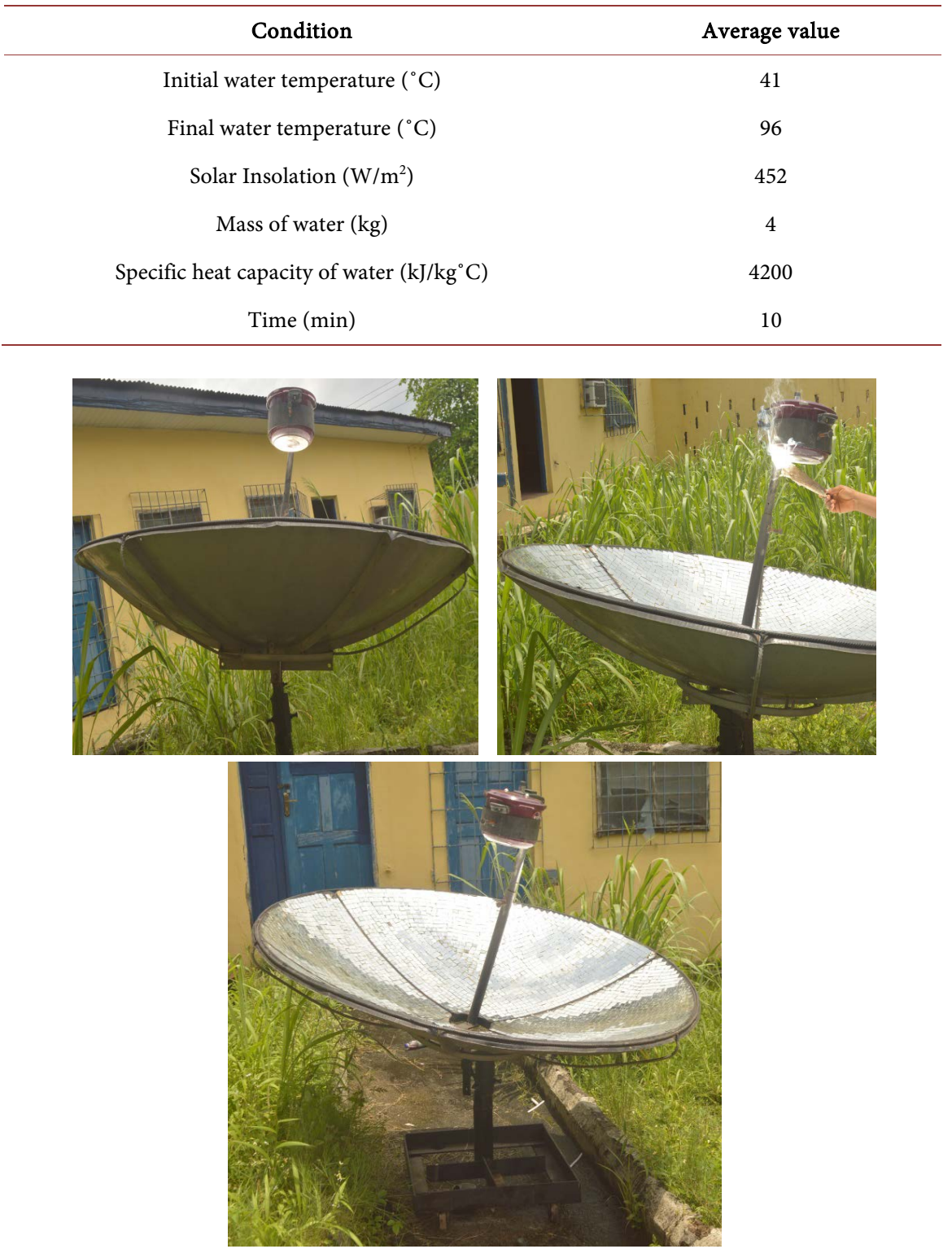

Figure 7. Domestic solar cooker in operation.

Results of the exergy analysis carried out on the DSC show that due to the solar radiation flux, $313.87 \mathrm{~J}$ of exergy is inputted to the DSC. $95.03 \%$ of this input exergy is destroyed due to the irreversibility of the system leaving the output exergy at a value of $15.61 \mathrm{~J}$, and exergy loss coefficient at 0.12 . Hence, the actual potential possessed by the DSC to extract heat from its surrounding and reflect it to the cooking pot is $4.97 \%$.

\section{Economic Analysis}

A breakdown of the cost of producing a unit of DSC is shown in Table 6 as US\$ $34(\mathrm{~N} 12,920.00)$. The aim of the economic analysis is to determine the payback time of acquiring the DSC. 
Table 6. Bill of Engineering Management and Evaluation Table.

\begin{tabular}{cc}
\hline Component & Cost \\
\hline Parabolic dish & $\$ 12.50$ \\
Stand & $\$ 6.50$ \\
Castor wheels & $\$ 2.50$ \\
Base & $\$ 5.50$ \\
Pot stand & $\$ 4.00$ \\
Glass mirror & $\$ 3.00$ \\
Total & US\$34.00 \\
\hline
\end{tabular}

In the rural south-eastern areas of Nigeria where biomass such as animal dung and firewood is used, firewood of US\$1 can cook 9 meals of beans for a family of 4. Beans meal is chosen for the analysis because of its longer cooking time than other staple foods. Considering an extreme case scenario, where 3 beans meals are served for a day, this means that US $\$ 1$ can serve the cooking energy requirement for 3 days in a Nigerian family of 4 in a rural setting. However, considering the operating time of the DSC which is between 10 am to $3 \mathrm{pm}$, only two meals can be cooked per day. The energy payback time for the DSC is calculated on this premise using Equation (11).

$$
q=(n \times \mathrm{R} \times \varepsilon) / \mathrm{h}
$$

where

q is the energy payback time,

$n$ is the number of cooking days for US $\$ 1$ cost of firewood,

$\mathrm{R}$ is the DSC acquisition cost,

6 is the firewood cost,

$\Sigma$ is the DSC cooking days factor $=1.5$.

Using equation 11, the energy payback time is 153 days. This implies that DSC is low cost and economically viable and as a result, is suitable in the rural areas. Also, due to its passive nature, the cost of maintenance is reasonably low as only occasional lubrication of the brackets (which enables manual tracking) and cleaning of the reflective surfaces are the major maintenance works required.

\section{Conclusions}

This work evaluated the thermal performance of a domestic solar cooker (DSC) with parabolically shaped polished glass mirror reflective surface following the method stipulated in the ASAE S58 (2003) as stated by P. A. Funk in his solar energy works. The followings are the conclusions from the analysis of the data incorporating the parameters detailed in exergy technique:

- Evaluation of data obtained from 22 tested based on a chosen temperature difference of $50^{\circ} \mathrm{C}$ and a regression model fit of the data established the standardized cooking power to be $618.5 \mathrm{~W}$ with an overall thermal efficiency of $48.67 \%$ which is a very far improvement on earlier result of $17.5 \%$ ob- 
tained by Dasin [5] with a similar DSC in Nigeria.

- Although the exergy potential of the DSC to extract heat from the ambient and reflect it on the pot is $4.97 \%$ (95.03\% is dissipated), this serves as an area for improvement of DSC particularly on the perfectness of the parabolic shape.

- On the whole, these results are comparatively thermally stable, usable and point areas of attention for improvement to minimize system irreversibility and upgrade the exergy potential.

- The ease of use and quickness in meal cooking during sunlight days provide very viable alternative to other sources of fuel for preparing meals in the Nigerian rural setting once the initial finance investment of N12,920.00 (US\$34) is made.

\section{Conflicts of Interest}

The authors declare no conflicts of interest regarding the publication of this paper.

\section{References}

[1] Augustina, A.O. and Innocent, O. (2015) Encroaching Desert Fuels Conflict in Northern Nigeria.

https://climate.earthjournalism.net/2015/12/11/encroaching-desert-fuels-conflict-in -northern-nigeria/index.html\#: :text=Reports\%20say\%20that\%20Nigeria\%20loses, and $\% 20$ its\%20most $\% 20$ populous\%20region

[2] Abdulfatai, I.A., Okunlola, A., Akande, W.G., Momoh, L.O. and Ibrahim, K.O. (2014) Review of Gully Erosion in Nigeria: Causes, Impacts and Possible Solutions. Journal of Geosciences and Geomatics, 2, 125-129.

[3] Iwuoha, A.U. and Ogunedo, M.B. (2019) Design and Construction of a Domestic Solar Cooker. Engineering and Technology Quarterly Reviews, 2, 24-37.

[4] Farooqui, S.Z. (2013) A Gravity Based Tracking System for Box Type Solar Cookers. Solar Energy, 92, 62-68. https://doi.org/10.1016/j.solener.2013.02.024

[5] Lahkar, P.J. and Samdarshi, S.K. (2010) A Review of the Thermal Performance Parameters of Box Type Solar Cookers and Identification of Their Correlations. Renewable and Sustainable Energy Reviews, 14, 1615-1621. https://doi.org/10.1016/j.rser.2010.02.009

[6] Muthusivagami, R.M., Velraj, R. and Sethumadhavan, R. (2010) Solar Cookers with and without Thermal Storage-A Review. Renewable and Sustainable Energy Reviews, 14, 691-701. https://doi.org/10.1016/j.rser.2008.08.018

[7] Mahavar, S., Sengar, N., Rajawat, P., Verma, M. and Dashora, P. (2012) Design Development and Performance Studies of a Novel Single Family Solar Cooker. Renewable Energy, 47, 67-76.

[8] Farooqui, S.Z. (2015) Angular Optimization of Dual Booster Mirror Solar Cookers-Tracking Free Experiments with Three Different Aspect Ratios. Solar Energy, 114, 337-348. https://doi.org/10.1016/j.solener.2015.01.030

[9] Farooqui, S.K. (2015) An Improved Power Free Tracking System for Box Type Solar Cookers. Solar Energy, 120, 100-103. https://doi.org/10.1016/j.solener.2015.07.021

[10] Farooqui, S.Z. (2013) A Vacuum Tube Based Improved Solar Cooker. Sustainable 
Energy Technologies and Assessments, 3, 33-39.

https://doi.org/10.1016/j.seta.2013.05.004

[11] Ashok, K. (1998) A Review of Solar Cooker Designs. TIDE (TERI Information Digest on Energy), 8, 1-37.

[12] Dasin, Y.D. (2013) Thermal Performance Testing of Parabolic Solar Cooker Using New World Standard Procedure. International Journal of Engineering Research and Technology, 6, 323-331.

[13] Funk, P.A. (2000) Evaluating the International Standard Procedure for Testing Solar Cookers and Reporting Performance. Solar Energy, 68, 1-7. https://doi.org/10.1016/S0038-092X(99)00059-6

[14] Tiwari, G.N. (2002) Solar Energy: Fundamentals, Design, Modelling and Applications. Alpha Science International, Oxford.

[15] Ogunedo, B.M. and Okoro, V.I. (2017) Exergy Analysis of Afam IV Gas Turbine Power Plant. Mechanical Engineering - Elixir International Journal, 105, 46222-46225.

[16] Ozturk, H.H. (2004) Experimental Determination of Energy and Exergy Efficiency of the Solar Parabolic-Cooker. Solar Energy, 77, 67-71.

https://doi.org/10.1016/j.solener.2004.03.006 